\title{
Gribb, Kelly, and Larson receive MRS Innovations in Materials Characterization Award
}

T ye T. Gribb of DTE Research and Development LLC, and Thomas F. Kelly and David J. Larson of Cameca Instruments, Inc. have been honored with the MRS Innovations in Materials Characterization Award for their joint work on a local-electrode atom-probe tomograph. Gribb, Kelly, and Larson are cited for "the highly successful conception, design, fabrication, and commercialization of an ergonomic three-dimensional local-electrode atom probe (LEAP) tomograph that enables the determination of the local composition information, on an atom-by-atom basis, of metallic, semiconducting, ceramic and organic mate-
MRS rials, on a subnanometer scale, in direct space, with high mass tributions and developments in instrumentation, specimen preparation, and data interpretation relating to the atom probe technique. The instruments they developed enable microstructural characterization of complex materials to the atomic level.

The development of their three-dimensional (3D) LEAP tomograph began as a concept in a research program at the University of Wisconsin, Madison, which was headed by Kelly. During 1993 to 1998 , Kelly and Larson demonstrated the feasibility of the concept, fabricated local electrodes, and prepared microtip specimens that could take advantage of the local-electrode geometry.

While the key concepts for the LEAP tomography were proven to work, the researchers had yet to build an operating instrument. Kelly founded Imago Scientific Instruments through which the prototype of a commercial LEAP tomography was designed and fabricated with Gribb serving as the lead designer.

Their instrument delivered the requisite advances need

resolving power and signal-to-noise ratio, permitting the determination of small concentrations of all elements." The research team will present an award talk at the 2011 Materials Research Society Spring Meeting in San Francisco. The award has been endowed by Toh-Ming Lu and Gwo-Ching Wang.

Gribb, Kelly, and Larson made individual and also joint innovative con- to make an ergonomic atom probe tomography for materials research, namely: (1) high data collection rates $\left(>10^{6}\right.$ atoms/min); (2) a large field of view $\left(200 \times 200 \mathrm{~nm}^{2}\right)$; (3) high mass resolution (better than 1 part in 1200 full-width half maximum); and (4) microtip specimens that could be placed on an array of 36 silicon microrods, using a commercial dual-beam focused ion beam micro- scope. With this instrument, what used to take weeks of data collection would now take minutes and the $200 \mathrm{~nm}$ field of view opened up the application space to technologically relevant structures such as transistors and multiphase metals and ceramics.

The realization of the ergonomic 3D LEAP tomograph required the development of specimen preparation methodologies, an effort led by Larson.

In April 2010, Imago Scientific Instruments Corporation was acquired by Ametek, Inc., the parent company of Cameca Instruments, Inc. Imago's operations are now fully part of Cameca.

Gribb served as vice president of research and development and vice president of instrumentation at Imago Scientific Instruments from 1998 to 2010 . He received his MS (1993) and $\mathrm{PhD}$ (1998) degrees in metallurgical engineering from the University of Wisconsin, Madison. He has five patents and over 15 publications.

Kelly is division vice president responsible for atom probe technology and operations at Cameca Instruments, Inc. He received his PhD degree (1981) in materials science from the Massachusetts Institute of Technology. Among his awards are the Presidential Science Award from the Microbeam Analysis Society (2008) and part of the Image team receiving three R\&D 100 Awards (2004, 2006, and 2008). He has 10 patents issues and pending and over 150 publications.

Larson is director of atom probe technology at Cameca Instruments, Inc. He received his $\mathrm{PhD}$ degree (1996) in materials science from the University of Wisconsin, Madison. His honors include the position of Visiting Scholar in Corpus Christi College at the University of Oxford, honorary staff in the Key Centre for Microscopy and Microanalysis at the University of Sydney, and the Cosslett Award for Outstanding Invited Paper from the Microbeam Analysis Society. Larson has 11 patents granted or pending and over 170 publications. 